\title{
Shared Transportation in Future Beijing
}

\author{
Yi Wang \\ Beijing Jiaotong University, Beijing 100044, China
}

\begin{abstract}
With repaid development of science and technology, various high-tech transportation has come into Chinese society. Moreover, with the further development of sharing economy in China, all kinds of shared transportation have gradually come into our society. In Beijing, it is nothing extraordinary to see shared bicycles stop at the roadside. However, with the popularity of shred transportation, many social problems have also aroused people's thinking. In this essay, we will be based on the contemporary science and technology develop situation to discuss how will the shared transportation be like and how will the shared transportation interact with people.
\end{abstract}

Keywords: Shared transportation, Shared bicycle, Beijing, Interaction, Designer.

\section{Introduction}

In recent years, with the rapid development of the Internet industry, the sharing economy has gradually become a hot issue in Chinese society (Jin \& Yao, 2020). In most Chinese cities' high streets and back lanes, people can always see a unique but familiar way of transportation - shared bicycles. Since the shared bicycle entered the Chinese market, it has provided great convenience for people's life. Moreover, with the further development of the sharing economy, people gradually set their sights on the broader market of shared transportation. At the same time, with the further improvement of the Internet service industry, there will be more kinds of shared transportation put into the Chinese market in future. The emergence of various shared transportation has brought convenience to people's lives and caused people's thinking in the meantime. Why can shared transportation be so popular all over China in such a short time? What impact will share transportation have on people's lifestyle and living environment? How does shared transportation will be like in the future? Will it be as magical as shown in science fiction movies? This essay aims to develop more practicable methods for shared transportation's development based on the current science and technology situation.

The objective of this essay is to demonstrate shared transportation will become more functional with the technology development and make people's lives more effortless in the following decades. Firstly, this essay will introduce shared transportation and explain the interaction process between people and shared transportation. Secondly, this essay will be based on the current social reality of Beijing to analyze the impact of shared transportation. Moreover, from the perspective of sustainable development, this essay will explore the possible positive connections between shared transportation and people's living environment. Besides, this essay will also conceive the development of shared transportation in the next few decades and discuss what kinds of shared transportation will emerge into the Chinese market in future. Finally, this essay will summarize the possible changes that shared transportation will bring to people's lives and discuss the confusion that shared transportation may cause.

\section{Introduction to Shared Transportation}

Nowadays, with the development of the Internet service industry, all kinds of service apps emerge in an endless stream (Jacko, 2012). Moreover, with the popularity of smartphones in China, the Internet service industry has already penetrated almost every aspect of our life. Whether traveling or commuting, the Internet service industry has played an essential role in Chinese people's daily lives. Under the background of the Internet service industry's repaid development, the sharing economy has quickly become a hot spot since it comes to the public. Among the variety of shared economic services, shared transportation can be the most popular one.

However, what is "shared transportation"? Shaheen (2015) has explained that "shared transportation is an innovative transportation strategy which enables users to have short-term access to transportation modes on an 'as need' basis". Thus we can see that shared transportation is a new travel choice based on sharing economy. Moreover, with the increase of people's travel demand, more and more transportation has also poured into the Chinese market. Nowadays, with the popularity of shared bicycles, picking shared bicycles for short-term travel has already become a common choice for most Chinese people, and the shared bicycle has also become a part of Chinese people's daily lives. At the same time, the great success of shared bicycles in the Chinese market has also driven the development of other shared industrial chains (Chen, F. \& Wang, M., 2012). For example, the shared new energy vehicles have also gradually entered the Chinese market. In Beijing and the other big cities in China, some new energy vehicles have already been put into use.

When talking about shared transportation, an important point that needs to mention here is the "service app". In China, with the popularity of smartphones, people's use of smartphones is rapidly increasing, and the requirements for the functions of smartphones are also becoming higher. Under this background, all kinds of service apps have come into people's life. At the same time, the interaction between the user and the phone has also become more and more diverse. For example, if a user wants to hire a shared bicycle, the user only needs to open the app and scan the code on the bicycle, and the bicycle's lock will open after the user scan the code so that the 
user can own a shared bike for a short time. Here, this essay will take the shared bicycle as an example to discuss how the

user interacts with the shared bicycle by using a smartphone.

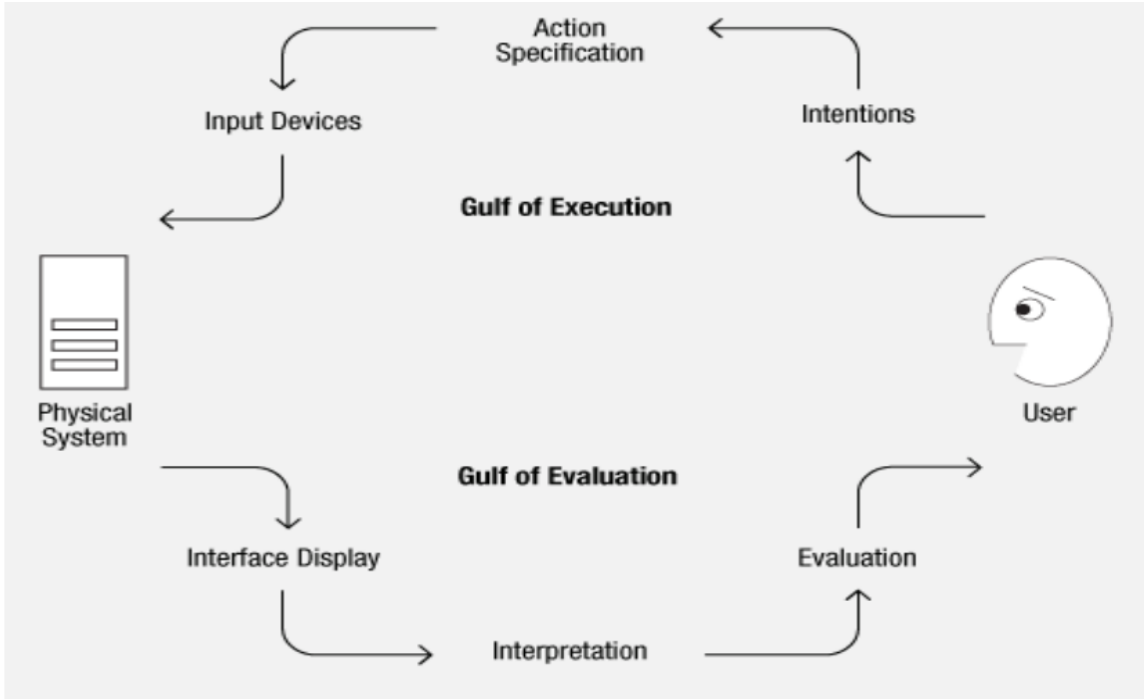

Figure 1: Don Norman's Gulf Model

Don Norman has put forward the gulf model to explain user interact with the physical system. Norman's interaction model can be mainly divided into two phases: "gulf of execution" and "gulf of evaluation", and the whole cycle explains an interaction process between the user and the device. When a user has a "goal", for example, the user thinks she needs a bicycle to go shopping, and this is the first stage of Don Norman's model, which requires the user to have the intention and know what to do. After then the user needs to take action, the user can use the service app on the phone to hire a shared bicycle, and that can be seen as the second stage- "action specification", the user takes action to find the bicycles and use the phone to scan the code on the shared bicycle. After scanning the code, the app will receive the order from the user and transfer information to the device (the shared bicycle), this is the third stage of the gulf model- "input devices", and stages one to three are collectively referred to as the gulf of execution.

In addition, the "gulf evaluation" stage is also involved in the process of people - smartphone's interaction. After the shared bicycle receives the information from the phone, the bicycle's electric lock will open. In addition, the user can receive the information and suggestions provided by the service app from the smartphone's interface-for example, the distance from departure to destination and the user guide. What is more, after the user receives the information from the phone, the user can also evaluate if the information is valuable, so do to check whether the bicycle has problems and can use for riding. The whole process mentioned above can be understood as the "gulf of evaluation", because in this process, the device (smartphone and the shared bicycle) has received the order from the user and made a corresponding response. Thus, we can understand it as the stage of "interface display" and "interpretation". Moreover, the user can also evaluate the information provided by the phone, and we can see it as the stage of evaluation. The whole process contains the interface display, interpretation and evaluation three stages. Therefore, we can compare this process to the "gulf evaluation".
The user using the smartphone interacts with the shared bicycle constitute a whole interaction process. Through the interaction process, the user uses the smartphone to hire a shared bicycle, and the user can finally ride the bicycle to go shopping. Only through quickly interaction can make the user's travel more efficiently, shared bicycle and the service app did a great job. Based on Don Norman's gulf model, we can understand that using the phone to hire a shared bicycle is an interaction. What's more, Don Norman's theory can also help us better understand the process of interaction. For example, people riding a bike is an interaction because when people ride a bike, they need to think about how to ride and control the bicycle while riding it. At the same time, the bicycle will also move forward with people's control. Therefore, we can understand that people ride a bike is people interact with the bike, and this is a kind of interaction. Moreover, there are many examples like this in our daily lives, such as driving a car, playing mobile games, and these activities can all be regarded as interaction.

\section{Shared Transportation in Beijing}

After discussing how the user interacts with the shared bicycle, we will now discuss shared transportation's development in Beijing. In Beijing, it is common to see that people are riding a shared bike on the street. Moreover, as one of the most developed cities in China, Beijing's shared transportation industry is also growing vigorously. In recent years, with the popularity of shared bicycles, all kinds of shared transportation have entered the Chinese market. In Beijing, it is not hard to find new energy shared vehicles on the street, and the shared vehicles have become a new hot spot in the "sharing chain" (Li, D. \& Yang, L., 2013). Don Norman (2004) has stated that "excellent design products can bring convenience to people's lives and affect people's daily living habits to a certain extent". From Norman's point of view, successful design products should be user-centric. Take a broad view of the Chinese society, shared transportation indeed makes people's life much easier. In Beijing, due to 
various travel restrictions (for example, the "odd-and-even license plate rule"), people sometimes have no choice but need to take crowded buses and subways. However, since shared transportation gradually entered the city, people now can just take out their mobile phones and scan the code to hire a shared car or shared bicycle for work. Since shared transportation comes to the public, it has brought great convenience to people's lives, especially in short distance travel. Moreover, with the development of science and technology, shared transportation will also become more advanced in the future.

\section{Sustainable Development and Shared Transportation}

Nowadays, with the increasingly severe environmental pollution and the gradual depletion of energy, sustainable development has become the focus in our society ( $\mathrm{Li}, \mathrm{D}$. \& Yang, L., 2013). The United Nations has put forward the global goals for sustainable development to call on all society sectors to pay attention to the social crisis and appeal to people to make our future world peaceful and prosperous (Holden, E. \& Linnerud, K., 2017). Facing so many challenging problems, how can shared transportation make people live a better life? With the development of science and technology, more and more eco-friendly materials are used in production. In addition, advanced technology also leads to the decline of raw material production costs, so that enterprises will also be willing to choose to use environmentally friendly materials (Baker, 2006).

Therefore, how can the Chinese operators make shared transportation materials more environmentally friendly while ensuring profitability? Usually, the manufacturers need to use plenty of metal materials in the production process of shared transportation (especially shared bicycles and shared vehicles). However, purchasing new metal materials will cost enterprises much money. Thus, the manufacturers can consider using recyclable waste materials to produce the shared transportation. On the one hand, using recyclable waste materials can save much money for the shard transportation company. On the other hand, processing the waste materials into transportation is a good way to reuse these waste materials to achieve recycling. In addition, putting the waste materials (especially metal materials) into producing new shared transportation can also make the waste materials play their value again. Using shared transportation is an environmentally friendly way to travel, and choosing shared transportation for travel is also a good way to improve environmental problems such as air pollution. In a word, developing shared transportation will contribute to achieving sustainable development.

\section{Shared Transportation in Future Beijing}

Nowadays, Beijing's transportation issue is becoming more and more serious. In addition, with the publication of various traffic restriction policies, people's daily travailing has also become more inconvenient than before. However, since shared transportation emerged in Beijing, people now can have more choices to travel. Therefore, how can shared transportation makes people's life easier? How will shared transportation help people in the future? Kun (2018) has stated that "Transportation in the future will be more user-friendly, and the new materials and new technology will also be used to produce the transports". From Kun's point of view, we can boldly imagine what the transportation in the future will be like, maybe in 20 or 30 years later, the size and shape of the transports can all be decided by the user, and the function of the transports will also be more comprehensive.

Moreover, in the future, with the further development of the sharing economy, probably people no longer need to purchase cars or bicycles by themselves, and the government will provide more shared transportation for people to use. Therefore, in future Beijing, maybe we will no longer see private vehicles on the streets, and the problem of traffic congestion will also be solved. Probably in the future, shared transportation with various functions will appear in the streets of Beijing. When people feel uncomfortable, they can choose a shared self-driving car to the hospital, and when people are going to work in a hurry, they can choose a small but fast vehicle to go to their company. Moreover, if people just want to hang out and relax, they can pick a shared bicycle to hang around just like what we usually do in our daily life.

However, how will the interaction between humans and transportation be like in the future? Nowadays, people usually use mobile phones to interact with shared transportation. For most young people in Beijing, it is common to use their phones to scan the code and hire a shared bicycle or shared vehicle. However, will people still use the phone to interact with shared transportation in future? Don Norman (2007) stated that "the designers should follow simple design rules to make the design products easier for users to adapt". Therefore, how can the designers make shared transportation more accessible for the users to operate? Can designers make the interaction process between the user and transportation more straightforward? Nowadays, fingerprint identification and face recognition technology has already been widely used in payment. However, when people need to pay for something, they still need to use their phone, for example, to pay for the shared bicycle. Raskin (2000) has claimed that "good design products are usually subversive, they can even change people's inherent habits". With the development of science and technology, people may no longer use smartphones to hire shared transportation 20 years later. Moreover, with the maturity of interactive technology, the interaction between user and transportation will also become more understandable and comprehensive.

According to Simon's (1996) point of view, "In the near future, artificial intelligence will be widely used in the production field, and people's daily necessities will also be more intelligent". Based on the current social reality, we can assume that face recognition technology can be used in shared transportation 20 years later. However, how can face recognition technology better combine with shared transportation? Tovey (2016) has stated that "For technology developers, the most efficient way to improve the 
transportation's overall performance is to do transformation based on the transportation's appearance and function". According to Tovey's view, designers can base on the characteristics of the transportation to install the face recognition device. For example, it can be an excellent choice to install the face recognition device onto the steering wheels of the cars and the handlebars of the bicycles. Therefore, when people forget to take their mobile phone or when their phone is powered off, they can hire a shared bicycle directly through the face recognition device instead of using a smartphone to scan the code.

Moreover, the face recognition device can also be more functional, and it can be provided with the voice dialogue function and system navigation function at the same time. When people want to go to a place, they do not know the exact position, they can talk to the device, and the device will give the users voice instructions after receiving the order from the user. Therefore, by interacting with the device in the shared transportation, the user can easily reach the destination. More importantly, users can save more time if they don't need to use their phone to scan the code and use the mobile GPS navigation while riding the bicycle. Thus, we can see those users directly interacting with the device in shared transportation can be more straightforward than users using the phone to interact with shared transportation. Norman (2013) has put forward the concept that "The good design is usually understandable, which can help the user quickly understand how to operate the design product". From Norman's point of view, if the designers can successfully add a functional device (which may include the function of face recognition, voice instruction and system navigation) into the shared transportation, that will make the interaction between people and shared transportation more efficiently and easily.

After discussing how the user will interact with shared transportation in future, now we will discuss what kinds of shared transportation will be in Beijing. In Beijing, shared cars and shared bicycles can be seen everywhere. However, expect for shared bicycles and shared cars, will people have more shared transportation in the future? Kolko (2010) has stated that "interesting design interaction can always arise people's interest to interact with the design product". From Kolko's view, it can be a good choice for designers to develop more kinds of shared transportation. Nowadays, skateboards and scooters are also popular travel tools among young people in Beijing. However, can technology developers turn the normal skateboard and scooter into shared transportation?

According to Kaptelinin and Bonnie (2009), "Scientific and technological progress is always the premise for interactive product's development". With scientific and technological support, interactive products will also become more comprehensive and functional in now and future. Therefore, to make the normal skateboard and scooter become the intelligence shared transportation, there are still many works that need the technicians to coordinate with designers. Brown (2008) has stated that "Effective teamwork will make the progress of the whole design team smoothly, and this is the key to the success of enterprises". Based on the travel tools' appearance, designers can select the appropriate place to install the intelligent device, and the technicians can help the designers solve the technical challenges. For example, maybe the designers can make the skateboard longer and wider, so that the technology technicians can make the intelligence device better fit the skateboard's shape. Perhaps in 20 years later, we can see people using shared skateboards and shared scooters on the road.

When talking about the different kinds of shared transportation, how will the different shared transportation provide service for different groups? Nowadays, we can see that the shared bicycles are customized based on the average height of adults, which may lead to many shorter adults or children feeling uncomfortable while riding the shared bicycle. Norman (2017) has stated that "Practicality is always the most concerning factor for users, although the interesting interaction can bring users a gratifying experience, practicality is often the primary consideration of most users". Therefore, based on the demands of different groups, the shared transportation company can produce different sizes of shared transportation. For example, the typical size bicycles may not be suitable for parts of females and teenagers. Thus, the shared transportation company can launch large, medium, and small-sized shared bicycles for users to choose from. By providing different types and sizes of shared transportation for users, the shared transportation company can gain more users recognition and earn more profits from the wider users group. What's more, with the further popularize of shared transportation, it will also become more common for people to choose shared transportation for travel in future, and this more environmentally friendly traveling way will also improve Beijing's ecological environment.

\section{Concerns about the Shared Transportation}

Although shared transportation has brought convenience to people's daily lives, it still has many shortcomings that need designers to improve. Kolko (2011) has mentioned that "Designers should always put the product safety factors in the first place, security factors should not be ignored while putting the product into use". Nowadays, people occur accidents while using shared transportation happens frequently. The safety of using shared transportation has always been a concern since shared transportation entered society. However, the security issue of shared transportation has not been appropriately solved. In addition, with the development of interactive technology and the new energy industry, there will be more kinds of shared transportation (For example, shared scooters, shared skateboard, self-driving shared vehicles) come into our society in the near future, and the security problem of the shared transportation could be more worrying in the future.

As this essay discussed earlier, based on the contemporary scientific and technological development situation, maybe the face recognition device will be added into the shared transportation. However, maintaining the daily operation of the device can be a tricky problem. Since anyone can use shared transportation, maybe the user will incautiously cause 
some damages to the device while using the transport. In addition, the shared transportation itself may also break down after long-term use. Therefore, the shared transportation company may need to spend time and energy to maintain the regular operation of the shared transportation. In a city with a large population like Beijing, maintaining the normal operation of various shared transportation would consume many workforce and material resources, which will also be a great burden for the company in future.

\section{Conclusion}

In conclusion, shared transportation has brought great convenience since it entered the public's life. Moreover, with the development of internet technology in recent years, the interaction between users and shared transportation has also become more directly and efficiently. In this essay, we firstly introduced what is shared transportation and the present shared transportation in Beijing. In addition, this essay based on Don Norman's gulf model explained how people interact with shared transportation through the smartphone. From Norman's theory, we can better understand how the interaction process between human and intelligence devices. Moreover, this essay also analyzed the development of shared transportation in Beijing and discussed why people living in Beijing prefer to choose shared transportation in their daily lives.

What's more, based on the topic of general interestsustainable development, this essay discussed how shared transportation can contribute to sustainable development and why sharing transport can better protect our ecological environment. More importantly, based on the current situation of science and technology in contemporary China, this essay discussed how shared transportation would interact with people in the near future. Besides, this essay also analyzed the concerns about shared transportation. When talking about shared transportation, probably most Chinese people will not be unfamiliar with shared bicycles and shared cars. Moreover, with the further development of interactive technology, the interaction between users and shared transportation will also become more straightforward and exciting in the future. In the future, with the continuous improvement of the social economy, people's requirements for the quality of life will also become higher, and shared transportation in the future can be more functional and humanized. Besides, with the widespread use of shared transportation in Beijing, perhaps the sharing transport will gradually replace traditional private cars in the future, and the air quality and ecological environment in Beijing will be greatly improved. In the end, hopefully, the shared transportation industry can have better development in the Chinese market.

\section{References}

[1] Banga, C., \& Weinhold, J. (2014). Essential mobile interaction design perfecting interface design in mobile apps. Upper Saddle River, NJ: Addison-Wesley.
[2] Baker, S. (2006). Sustainable development. London; New York: Routledge.

[3] Brown, T. (2008). Design Thinking. Harvard business review, 86(6), pp. 84-92.

[4] Chen, F., \& Wang, M. (2012). How shall we design the future vehicle for Chinese market. Work (Reading, Mass.), 41(1), pp. 4265-4272.

[5] Fishman, E. (2016). Bikeshare: A Review of Recent Literature. Transport reviews, 36(1), pp. 92-113.

[6] Jacko, J. (2012). The Human-Computer Interaction Handbook: Fundamentals, Evolving Technologies and Emerging Applications. Boca Raton: CRC Press LLC.

[7] Jin, Fanglei., \& Yao, Jianan. (2020). Mode choice analysis in urban transport with shared battery electric vehicles: A stated-preference case study in Beijing, China. Transportation research, 133(1), pp. 95-108.

[8] Holden, E. \& Linnerud, K. (2017). The Imperatives of Sustainable Development. Sustainable development, 25 (3), pp. 213-226

[9] Kaptelinin, V., \& Bonnie, N. (2009). Acting with technology: activity theory and interaction design. Cambridge, Massachusetts: MIT Press.

[10] Kolko, J. (2010). Thoughts on Interaction Design. Burlington: Elsevier Science.

[11] Kolko, J. (2011). Thoughts on interaction design a collection of reflections. Amsterdam: Elsevier.

[12] Kun, A. (2018). Human-machine interaction for vehicles: review and outlook. Boston, Massachusetts: Now Publishers.

[13] Li, D., \& Yang, L. (2013). Zero energy buildings and sustainable development implications-A review. Energy (Oxford), 54(1), pp. 1-10.

[14] Lögren, J. \& Stolterman, E. (2007). Thoughtful interaction design: A design perspective on information technology. Cambridge, Massachusetts: MIT Press.

[15] Marcus, A. (2013). The history of the future: Sci-fi movies and HCI. Interactions, 20(4), pp. 64-67.

[16] Marcus, A. (2015). HCI and User-Experience Design Fast-Forward to the Past, Present, and Future. London: Springer.

[17] Murray, J. (2012). Inventing the medium principles of interaction design as a cultural practice. Cambridge, Massachusetts: MIT Press.

[18] Nielsen, J. \& Budiu, R. (2013). Mobile usability. Berkeley: New Riders.

[19] Norman, D. (1998). The invisible computer: why good products can fail, the personal computer is so complex, and information appliances are the solution. Cambridge, Massachusetts: MIT Press.

[20] Norman, D. (2004). Emotional design why we love (or hate) everyday things. New York: Basic Books.

[21] Norman, D. (2007). The design of future things. New York: Basic Books.

[22] Norman, D. (2013). The design of everyday things. New York: Basic Books.

[23] Norman, D. (2017). Design, Business Models, and Human-Technology Teamwork. Research technology management, 60(1), 26.

[24] Raskin, J. (2000). The humane interface: new directions for designing interactive systems. Reading, Mass: Addison Wesley. 
[25] Penichet, V. \& Gallud, J. (2013). New Trends in Interaction, Virtual Reality and Modeling. London: Springer.

[26] Shaheen, S. (2015). Shared Mobility: Current Practices and Guiding Principle. Washington, DC: Federal Highway Administration.

[27] Simon, H. (1996). The Sciences of the artificial. Cambridge, Massachusetts: MIT Press

[28] Tovey, M. (2016). Design for transport: A user-centred approach to vehicle design and travel. London: Routledge.

[29] Raskin, J. (2000). The humane interface: new directions for designing interactive systems. Reading, Mass: Addison Wesley.

[30] Rosson, M. \& Carroll, J. (2002). Usability engineering: scenario-based development of human-computer interaction. San Fancisco: Academic Press.

[31] Robinson, R. (1994). "Things That Make Us Smart" by Donald Norman. Design issues, 10(1), pp. 77. 